\title{
Mini-CEX Sebagai Metode Penilaian Keterampilan Klinis Mahasiswa Program Pendidikan Kepaniteraan Klinik Fakultas Kedokteran Universitas Gadjah Mada - Studi Pendahuluan
}

Reza M. Munandar*, Yoyo Suhoyo**, Tridjoko Hadianto**

* Mahasiswa S1 Fakultas Kedokteran Universitas Gadjah Mada, Yogyakarta

** Fakultas Kedokteran Universitas Gadjah Mada, Yogyakarta

\begin{abstract}
Background: Mini-CEX was developed to assess clinical skills by direct observation. Mini-CEX as a clinical skills assessment tool had to fulfill four requirements: validity, reliability, effects on students, and practicality.

Objective: To understand validity, reliability, and feasibility of Mini-CEX as a clinical skills assessment tool in medical core clerkship program at Faculty of Medicine Universitas Gadjah Mada.

Method: Seventy four clerkship students from Internal Medicine and 42 clerkship students from Neurology Department were asked to do an observed Mini-CEX encounter for minimum amount of four in Internal Medicine and two in Neurology Department in the period of September 2010 to January 2011. The validity was analyzed with KruskalWallis method for Internal Medicine, and Mann-Whitney Method for neurology Department, reliability was analyzed based on $G$ coefficient, and feasibility was analyzed using descriptive statistic.

Result: Mini-CEX's validity is shown by $p<0,001$ in Internal Medicine and $p=0,250$ in Neurology Department, $G$ coefficient for Internal Medicine and Neurology Department is 0,98 and 0,61 respectively. Feasibility in Internal Medicine and Neurology Department is $79,7 \%$ and $100 \%$ respectively.

Conclusion: Mini-CEX is valid and reliable in Internal Medicine but not in Neurology Department. Feasibility is good for both Internal Medicine and Neurology Department.
\end{abstract}

Keywords: Mini-CEX, validity, reliability, feasibility, internal medicine, neurology department

\section{Abstrak}

Latar belakang: Mini-CEX dikembangkan untuk menilai keterampilan klinis melalui observasi langsung. MiniCEX sebagai alat penilai keterampilan klinis harus memenuhi empat syarat: validitas, reliabilitas, dampak terhadap mahasiswa, dan kepraktisan.

Tujuan: Mengetahui validitas, reliabilitas, dan keterlaksanaan Mini-CEX sebagai alat penilai keterampilan klinis pada mahasiswa program kepaniteraan klinik di FK UGM.

Metode: Tujuh puluh empat mahasiswa kepaniteraan klinik dari Bagian IPD dan 42 mahasiswa dari Bagian Saraf melakukan Mini-CEX sebanyak minimal empat kali di Bagian IPD dan dua kali di Bagian Saraf dengan diobservasi oleh dosen klinis di RSUP Sardjito selama periode September 2010 hingga Januari 2011. Validitas Bagian IPD dianalisis dengan metode Kruskal-Wallis dan di Bagian Saraf menggunakan Mann-Whitney, reliabilitas dilihat berdasarkan koefisien $G$, dan keterlaksanaan dijabarkan menggunakan statistik deskriptif.

Hasil: Validitas di Bagian IPD ditunjukkan dengan $p<0,001$ sedang di Bagian Saraf $p=0,250$. Koefisien $G$ di Bagian IPD adalah 0,98 dan di Bagian Saraf 0,61. Keterlaksanaan Bagian IPD adalah 79,7 \% sedang di Bagian Saraf $100 \%$.

Kesimpulan: Validitas dan reliabilitas Mini-CEX baik di Bagian IPD namun tidak demikian di Bagian Saraf. Keterlaksanaan Mini-CEX pada kedua Bagian bisa dikatakan baik.

Kata Kunci: Mini-CEX, validitas, reliabilitas, keterlaksanaan, bagian IPD, bagian Saraf

Korespondensi: yo2suhoyo@yahoo.com ,Telp: 0274-562139

Bagian Pendidikan Kedokteran FK UGM, Gd. Radiopoetro Lt 6. Jl. Farmako Sekip Utara Yogyakarta 


\section{PENDAHULUAN}

Penilaian keterampilan klinis untuk mahasiswa program kepaniteraan klinik agar menghasilkan outcome yang berkompetensi selalu menjadi tantangan. Fakultas Kedokteran Universitas Gadjah Mada terus menerus melakukan inovasi dan meningkatkan sistem kepaniteraan klinik. Salah satu inovasi dan peningkatan yang dapat dilakukan adalah dengan menambah kualitas supervisi klinik, terutama dengan observasi langsung dan umpan-balik pada performa klinis mahasiswa. Hal ini dapat dilakukan dengan mengimplementasikan MiniCEX sebagai metode penilaian.

Mini-CEX merupakan instrumen objektif yang menilai mahasiswa berdasarkan performa mereka. ${ }^{1,2}$ Ia menawarkan kesempatan pada mahasiswa untuk melakukan kontak dengan pasien dengan kasus yang bervariasi untuk diobservasi secara langsung oleh dosen klinis. Hasil penilaian dapat digunakan untuk memberi umpan-balik yang membangun pada performa mahasiswa sehingga akan mendorong mahasiswa untuk belajar. ${ }^{3,4,5,6,7}$

Mini-CEX mempunyai validitas dan reliabilitas yang telah dibuktikan sebagai alat penilaian pada pelatihan dokter spesialis ${ }^{8,9,10}$ dan pada kepaniteraan klinik mahasiswa undergraduate. ${ }^{11}$ Mini-CEX juga telah dibuktikan cocok untuk meningkatkan kompetensi klinis pada mahasiswa kedokteran. ${ }^{2,12}$

Bagaimanapun, agar Mini-CEX dapat dijadikan alat penilai keterampilan klinis di FKUGM, ada empat syarat yang harus diuji yaitu, validitas, reliabilitas, dampak terhadap mahasiswa, dan kepraktisan.

\section{METODE}

Total sejumlah 116 mahasiswa kepaniteraan klinik dari Bagian Ilmu Penyakit Dalam (IPD) dan Saraf selama September 2010 hingga Januari 2011 diminta untuk melakukan Mini-CEX yang diobservasi oleh dosen klinis dengan jumlah minimal pelaksanaan Mini-CEX di Bagian IPD adalah empat kali dan di Bagian Saraf dua kali.

Terdapat tujuh poin yang dinilai dengan Mini-CEX yakni, anamnesis, pemeriksaan fisik, keputusan klinis, komunikasi/konseling,profesionalisme, pengorganisasian/ efisiensi, dan penanganan pasien secara keseluruhan. Nilai dari ketujuh poin itu kemudian dijumlahkan dan diambil rata-ratanya untuk dianalisis.
Uji normalitas dilakukan dengan uji KolmogorovSmirnov. Validitas Mini-CEX dianalisis dengan metode Kruskal-Wallis untuk Bagian IPD dan Mann-Whitney untuk Bagian Saraf. Reliabilitas Mini-CEX dianalisis dengan menghitung koefisien G. Keterlaksanaan MiniCEX dianalisis dengan statistik deskriptif. Validitas dan keterlaksanaan dianalisis dengan menggunakan program SPSS ver. 18.0. Koefisien $G$ dihitung menggunakan program Edu G ver. 6.0.

Penting dijadikan catatan bahwa validitas yang diuji pada penelitian ini bukanlah suatu validitas murni. Validitas yang dimaksudkan adalah kemampuan Mini-CEX dalam membedakan performa mahasiswa yang melakukan Mini-CEX untuk pertama kali, kedua, ketiga, dan keempat kalinya.

\section{HASIL}

Selama September 2010 hingga Januari 2011, 74 orang mahasiswa kepaniteraan klinik Bagian Ilmu Penyakit Dalam, dan 42 orang mahasiswa kepaniteraan klinik Bagian Saraf telah berpartisipasi dalam penelitian ini. Lima mahasiswa dari Bagian Penyakit Dalam dieksklusi karena memberikan data Mini-CEX dengan form yang berbeda dengan yang telah ditetapkan untuk digunakan dalam penelitian ini, dan 14 mahasiswa dieksklusi karena tidak melakukan Mini-CEX sebanyak minimal 4 kali. Sepuluh orang mahasiswa kepaniteraan klinik Bagian Saraf tidak mengembalikan buku Mini-CEX, sehingga jumlah mahasiswa kepaniteraan klinik yang memenuhi kriteria inklusi berjumlah 55 orang dari Bagian Ilmu Penyakit Dalam, dan 32 orang dari Bagian Saraf.

Selama penelitian ini, mahasiswa kepaniteraan klinik telah melaksanakan Mini-CEX sebanyak 269 kali untuk Bagian Ilmu Penyakit Dalam dengan dievaluasi oleh 40 orang residen klinis dan dokter spesialis (dosen klinis). Nilai rata-rata Mini-CEX pertama, kedua, ketiga, dan keempat secara berurutan adalah 78,09 (SD = 7,21); 86,39 $(\mathrm{SD}=3,17) ; 86,17(\mathrm{SD}=2,48)$; dan 86,56 $(\mathrm{SD}=2,94)$. Kasus-kasus yang dijumpai selama pelaksanaan MiniCEX beragam seperti Ca Paru, CHF, CKD, ulkus DM, diare amoebiasis, efusi pleura, TB paru, hepatomegali, hipertensi, leukemia akut, PPOK, sirosis hepatis, dengue fever, dengue haemorrhagic fever, tifoid, paratifoid, malaria, asma bronkial, bronkopneumonia, dispepsia, kolik abdomen, hepatitis, lymphadenopathy, hipoglikemi, leptospirosis, thalasemia, anemia, angina pectoris stabil, DM, SLE, dan MS, dengan pelaksanaan Mini- 
CEX terbanyak dilaksanakan di unit rawat inap $(52,9$ $\%)$, kemudian unit rawat jalan (2,2 \%), dan Unit Gawat Darurat $(1,1 \%)$, sisanya $(43,8 \%)$ tidak mengisikan tempat pelaksanaan Mini-CEX.

Di Bagian Saraf, dari 84 kali pelaksanaan Mini-CEX yang diawasi dan dievaluasi oleh 12 orang dokter spesialis sebagai dosen klinis, pelaksanaan terbanyak dilakukan di unit rawat inap (23,4\%), rawat jalan (10,9\%) dan sisanya tidak mengisi tempat pelaksanaan Mini-CEX $(65,7 \%)$ dengan kasus-kasus yang ditemui seperti Bell's Palsy, cephalgia, contussio cerebri, epilepsi, cedera kepala, hemiparese, LBP, SH, SNH, cedera spinal, vertigo, tension-type headache, stroke hemoragik dan non hemoragik, meningoencepalitis, neuropati DM, dan penurunan kesadaran. Rata-rata nilai Mini-CEX pertama dan kedua secara berurutan adalah $88,44(\mathrm{SD}=5,48)$ dan $90,29(\mathrm{SD}=4,25)$.
Uji Kolmogorov-Smimov yang dilakukan pada penelitian ini menunjukkan bahwa nilai Mini-CEX di Bagian IPD dan Saraf tidak terdistribusi normal $(\mathrm{p}<0,005)$. Hasil uji Kruskal-Wallis menunjukkan kemungkinan adanya perbedaan yang bermakna antara nilai Mini-CEX pertama, kedua dan seterusnya di Bagian IPD $(p<0,005)$. Analisis posthoc kemudian menunjukkan bahwa ada perbedaan bermakna antara nilai Mini-CEX pertama dengan kedua, ketiga, dan keempat, namun tidak ada perbedaan bermakna antara nilai Mini-CEX kedua, ketiga, dan keempat. Tidak ada perbedaan bermakna antara nilai Mini-CEX pertama dan kedua di Bagian Ilmu Penyakit Saraf ( $p>0,005)$ dengan menggunakan metode Mann-Whitney. Reliabilitas Mini-CEX baik di Bagian IPD $(G>0,8)$ namun tidak di Bagian Saraf $(G<$ 0,8). Keterlaksanaan Mini-CEX di Bagian IPD 79,7 \% dan di Bagian Saraf $100 \%$.

Tabel 1. Hasil analisis validitas, reliabilitas, dan keterlaksanaan Mini-CEX

\begin{tabular}{cccc} 
Bagian & Validitas & Reliabilitas & Keterlaksanaan \\
$\begin{array}{c}\text { Ilmu Penyakit } \\
\text { Dalam }\end{array}$ & $\mathrm{P}<0,001$ & $\mathrm{G}=0,98$ & $79,7 \%$ \\
\hline Saraf & $\mathrm{P}=0,250$ & $\mathrm{G}=0,61$ & $100 \%$ \\
\hline
\end{tabular}

\section{PEMBAHASAN}

Hasil penelitian ini mendukung validitas Mini-CEX seperti yang telah ditunjukkan oleh penelitian-penelitian terdahulu, seperti penelitian yang dilakukan ${ }^{9}$, dimana untuk setiap keterampilan klinik residen, staf penilai dapat membedakan 3 tingkat kemampuan residen (tidak memuaskan, memuaskan, superior) dan dari penilaian tiga tingkat kemampuan tersebut didapatkan hasil berbeda bermakna. Studi ini merupakan studi pertama tentang construct validity Mini-CEX. Durning menyebutkan bahwa ada korelasi yang kuat antara skor Mini-CEX dan skor ABIM MEF terkait serta skor ITE. Adanya korelasi bermakna antara skor Mini-CEX dan nilai akhir mahasiswa kepaniteraan klinik, nilai ujian dan ujian tertulis juga disebutkan oleh Kogan. ${ }^{11}$ Norcini $^{2}$ menyebutkan bahwa residen mengalami peningkatan yang signifikan dalam semua aspek Mini-CEX dibanding tahun pertamanya, Mini-CEX juga menunjukkan korelasi cukup terhadap ujian nasional spesialisasi yang dilaksanakan. ${ }^{10}$ Menurut Wiles ${ }^{12}$ Mini-CEX terbukti meningkatkan kemampuan mahasiswa sesuai dengan tingkat senioritas. Hasil- hasil ini mendukung validitas Mini-CEX

Hasil reliabilitas pada penelitian ini juga mendukung hasil penelitian sebelumnya seperti pada penelitian oleh Durning, Hatala, dan Kogan yang menyatakan bahwa Mini-CEX mempunyai reliabilitas yang dapat dipertanggungjawabkan dan mempunyai reliabilitas internal yang sangat baik., ${ }^{5,10,11}$ Mini-CEX menunjukkan reliabilitas yang sangat baik sebagai metode untuk memperoleh umpan-balik untuk peningkatan keterampilan diri saat digunakan untuk menilai dokter praktek puskesmas. ${ }^{12}$

Keterlaksanaan Mini-CEX yang baik seperti pada penelitian ini juga ditunjukkan oleh studi oleh Kogan dan Hauer yang menunjukkan bahwa Mini-CEX dapat dilaksanakan pada mahasiswa kepaniteraan klinik dengan pasien rawat jalan dan inap sebagai penilaian formatif. ${ }^{5,11}$ Keterlaksanaan Mini-CEX yang baik juga 
ditunjukkan oleh hasil studi Torre ${ }^{13}$ dengan menggunakan Mini-CEX berbasis PDA, selain itu keterlaksanaannya juga baik di Bagian Saraf ${ }^{12}$, Bagian Anestesi ${ }^{14}$, dan Bagian Ilmu Penyakit Dalam ${ }^{8}$. Walaupun studi oleh De Lima menyatakan bahwa Mini-CEX tidak layak ${ }^{6}$, namun dapat dipertimbangkan sebagai suatu alat penilaian yang bernilai sebagaimana ditunjukkan oleh hasil penilaian evaluator dan residen.

Walaupun pada penelitian ini Mini-CEX valid dan reliabel di Bagian Ilmu Penyakit Dalam, namun tidak demikian halnya dengan Bagian Saraf. Hasil yang berbeda ini mungkin dikarenakan sedikitnya data sampel yang diperoleh dari Bagian Saraf karena waktu penelitian yang singkat, dan juga karena pelaksanaan minimal Mini-CEX di Bagian Saraf hanya dua kali, bukannya empat kali seperti di Bagian Ilmu Penyakit Dalam.

\section{KESIMPULAN}

Mini-CEX mempunyai validitas yang baik di Bagian Ilmu Penyakit Dalam namun di Bagian Saraf validitasnya tidak baik. Mini-CEX menunjukkan reliabilitas yang baik di Bagian Ilmu Penyakit Dalam dengan jumlah minimal Mini-CEX adalah empat kali, namun tidak demikian halnya di Bagian Saraf yang jumlah minimal Mini-CEXnya hanya dua kali. Mini-CEX memiliki keterlaksanaan yang baik, yaitu di Bagian Ilmu Penyakit Dalam 79.7 \%, sedang keterlaksanaan di Bagian Saraf $100 \%$.

\section{SARAN}

Perlu dilakukan penelitian serupa dengan jumlah sampel yang lebih besar lagi, dilakukan penambahan jumlah minimal Mini-CEX menjadi sebanyak empat kali di Bagian Saraf agar menunjukkan hasil yang valid dan reliabel.

Oleh karena Mini-CEX menunjukkan hasil yang valid, maka Mini-CEX dapat digunakan di bagian lain dengan modifikasi yang disesuaikan dengan bagian, dan perlu dilakukan penelitian dengan melibatkan lebih banyak bagian-bagian kepaniteraan klinik lainnya sehingga dapat menunjukkan kecocokan Mini-CEX sebagai alat penilai keterampilan klinis di bagian lain.

\section{UCAPAN TERIMAKASIH}

Ucapan terimakasih kami sampaikan kepada dr. Ova Emilia, M.Med.Ed, Ph.D, Sp.OG(K), atas bantuan dan bimbingannya dalam penelitian ini.

\section{DAFTAR PUSTAKA}

1. Norcini JJ. The mini clinical evaluation exercise (miniCEX). The Clin Teach. 2005;2(1): 25-30.

2. Norcini JJ, Blank LL, Duffy D, Fortna, GS. The miniCEX: a method for assessing clinical skills. Ann Intern Med 2003;138:476-81.

3. Hauer KE. Enhancing feedback to students using the mini-CEX (clinical evaluation exercise). Acad Med. 2000;75:524.

4. Holmboe ES, Hawkins RE, Huot SJ. Effects of training in direct observation of medical residents' clinical competence. Ann Intern Med. 2004;140:874-81.

5. Kogan JR, Hauer KE. Brief report: use of the miniclinical evaluation exercise in internal medicine core clerkships. J Gen Intern Med. 2006;21:501-2.

6. De lima AA, Henquin R, Thierer J, Paulin J, Lamari S, Belcastro F, \& Van der vleuten CPM. A qualitative study of the impact on learning of the mini clinical evaluation exercise in postgraduate training. Med Teach. 2005;27(1):46-52.

7. Norcini J, Burch V. Workplace-based assessment as an educational tool: AMEE guide no. 31. Med Teach. 2007;29 (9):855-71.

8. Durning SJ, Cation LJ, Market RJ, Pangaro LN. Assessing the reliability and validity of the mini clinical evaluation exercise for internal medicine residency training. Acad Med. 2002;77:900-4.

9. Holmboe ES, Huot S, Chung J, Norcini J, \& Hawkins RE. Construct validity of the mini clinical evaluation exercise (mini-CEX). Acad Med. 2003;78(8):826-30.

10. Hatala R, Ainslie M, Kassen BO, Mackie I \& Roberts $\mathrm{JM}$. Assessing the mini-clinical evaluation exercise in comparison to a national specialty examination. Med Ed. 2006;40:950-6.

11. Kogan JR, Bellini LM, \& Shea JA. Feasibility, reliability and validity of the mini clinical evaluation exercise (mini-CEX) in a medicine core clerkship. Acad Med. 2003;78:33-5.

12. Wiles CM, Dawson K, Hughes TAT, Llewelyn JG, Morris HR, Pickersgill TP, Robertson NP, Smith PEM. Clinical skills evaluation of trainees in a neurology department. Clin Med. 2007;7(4):365-9.

13. Torre DM, Simpson DE, Elnicki DM, Sebastian JL, Holmboe ES. Feasibility, reliability, and user satisfaction with PDA-based mini-CEX to evaluate the clinical skills of third-year medical students. Teaching and Learning in Medicine. 2007;19:271-7.

14. Weller JM, Jolly B, Misur MP, Merry AF, Jones A, Crossley JGM, Pedersen K, Smith K. Mini-clinical evaluation exercise in anesthesia training. J Anesth. 2009; 102:633-41. 